\title{
An Extensive Usage of Hand-Held Devices will Lead to Musculoskeletal Disorder Among Paramedical Students of Parul University
}

Section: Healthcare

ISI Impact Factor

(2019-20): 1.628

IC Value (2019): 90.81

SJIF (2020) $=7.893$

(c) (i) (8)

Copyright@IJCRR

\section{Didhiti D1, Ishita G², Umang V'2, Darshana C²}

'Assistant Professor, Parul Institute of Physiotherapy, Parul University, Limda, Vadodara, Gujarat, India; ${ }^{2}$ Physiotherapist, Parul Institute of Physiotherapy, Parul University, Limda, Vadodara, Gujarat, India.

\section{ABSTRACT}

Introduction: The usage of hand-held device is increasing with within the adolescents consistent with survey conducted in China, in the year 2018 the share of individuals using smartphones has drastically increased up to $98.6 \%$.consistent with a study conducted by Alphas an et al. in the year 2016 there have been about $52.7 \%$ males and $46.9 \%$ females who were having their age between 18 to 23 and that they were considered to be addicted for the usage of smartphones. consistent with a study conducted by Alosaimi et al. about $27.2 \%$ of people are coming under the age of 20 to 24 years who were using their smartphones for over 8 hours.

Topic: An extensive usage of hand-held devices will lead to musculoskeletal disorder among paramedical students of Parul University.

Objective: The objective of this study is to find the prevalence of musculoskeletal disorder in the upper extremity among students of Parul University due to extensive usage of hand-held devices. As the usage of the hand-held device is increasing nowadays.

Method: The subjects were paramedical students at Parul University. 215 subjects were included in this study out of which 209 were selected based on inclusion and exclusion criteria, the data was collected through a google form.

Outcome Measure: DASH questionnaire.

Results: Results showed that there was a moderate prevalence of musculoskeletal disorder within the upper extremity due to extensive usage of hand-held devices among paramedical students of the Parul University.

Conclusion: Hand-held devices have become a crucial part of life. However, their extensive usage may lead to musculoskeletal disorders keeping this into considerations, further studies should be done in future for spreading awareness among the users.

Key Words: Hand-held device, Extensive, Typing, Musculoskeletal disorders, DASH, Cell phone, Upper extremity

\section{INTRODUCTION}

Hand-held device are those devices that can be carried easily by one's hand. 'Device like Tab, Cell-phone, Personal data assistants (PADs), iPod and gaming device are kind of handheld devices. ${ }^{2}$ Hand-held devices are having multiple uses like chatting, for calling, sending e-mails, for enjoying games and other entertainment and academic purposes. ${ }^{3}$ Nowadays their usage is increasing worldwide.

The usage of hand-held device is increasing with within the adolescents. ${ }^{4}$ consistent with survey conducted in China, in the year 2018 the share of individuals using smartphones has drastically increased up to $98.6 \%$. ${ }^{4}$ Consistent with a study conducted by Alphas et al. in the year 2016 there have been about $52.7 \%$ males and $46.9 \%$ females who were having their age between 18 to 23 and that they were considered to be addicted for the usage of smartphones. ${ }^{5}$ consistent with a study conducted by Alosaimietal. there are about $27.2 \%$ of people coming under the age of 20 to 24 years who were using their smartphones for over 8 hours. ${ }^{6,7}$

The usage of smartphones among students is over $80 \%$ and that they spend approximately 5- 6 hours each day. ${ }^{8,9} \mathrm{In}$ many studies it's been concluded that there is an increase in with within the usage of mobile among college and university students. ${ }^{10}$

\section{Corresponding Author:}

Dr. Didhiti Desai, Parul Institute of Physiotherapy, Parul University, Limda, Vadodara, Gujarat, India. Email: didhiti.desai@paruluniversity.ac.in

ISSN: 2231-2196 (Print) ISSN: 0975-5241 (Online)

Received: $07.01 .2021 \quad$ Revised: 23.02 .2021

Accepted: 12.03 .2021

Published: 12.09 .2021 
The increased usage of text messaging across the globe has raised concern that its use could lead to musculoskeletal disorders. Due to the increased usage of hand-held devices like smartphones, the rate of musculoskeletal disorders of the hand, wrist and forearm has also increased across the globe. ${ }^{3}$

Because of the long-term usage of the hand-held devices, there has been continuous mechanical stress on the structures like tendon, muscles and parametric tissues and it leads to problems in the thumb and the muscles within the forearm. ${ }^{3}$ Also, there's is the continuous movement of the wrist which ends within the musculoskeletal disorders. ${ }^{11,12}$ The musculoskeletal disorders are increasing within the upper extremity of college students by $32.9 \%$ and $89.3 \%$ among different parts of the globe. ${ }^{10}$

Musculoskeletal disorders are those injuries and disorders that affect the movements of the human body or musculoskeletal system. ${ }^{1}$ They're a group of inflammatory and degenerative conditions.

Outcome measures are important for the evaluation of the standard of life and performance. ${ }^{13}$ The measurement of disability is very important for a comprehensive assessment of outcome following injury within the upper limb. ${ }^{14}$

Measuring disabilities in patients with upper-limb disorders seem stapes a practical challenge, many distinct questionnaires are developed for the various regions of the upper limb. But due to of presence of multiple disorders or multiple affected regions in many patients, the selection available becomes difficult ${ }^{14}$

So, here Disabilities of the Arm, Shoulder and Hand outcome measure (the DASH) provides the solution.

\section{PROCEDURE}

\section{Materials}

Paper, Pen, Laptop, Calculator, DASH questionnaire.

\section{Methodology}

This study was a survey study conducted on paramedical students of Parul University. The info was collected by using the DASH questionnaire for knowing the prevalence of musculoskeletal disorders because of extensive usage of hand-held devices among paramedical students of the Parul University. The themes were selected on the idea of the following criteria:

\section{Inclusion Criteria}

- Age:18-25.

- Paramedical students of Parul University.

- More than 4hours.

\section{Exclusion Criteria}

- Having any injury in the upper extremity.

- Having any deformity in the upper extremity.

- Having any neurological problem because of other reasons.

\section{RESULT}

Results showed that among 209 students there were $145 \mathrm{Fe}-$ males and 64 Male and the mean DASH score obtained by data analysis was 43.6013 and the standard response mean was 8.77252 . So, the result strongly suggests that there is a presence of moderate difficulty in arm, shoulder and hand among the paramedical students of Parul University.

\begin{tabular}{|c|c|}
\hline & DASH \\
\hline MEAN & 43.6 \\
\hline SD & 8.7 \\
\hline
\end{tabular}

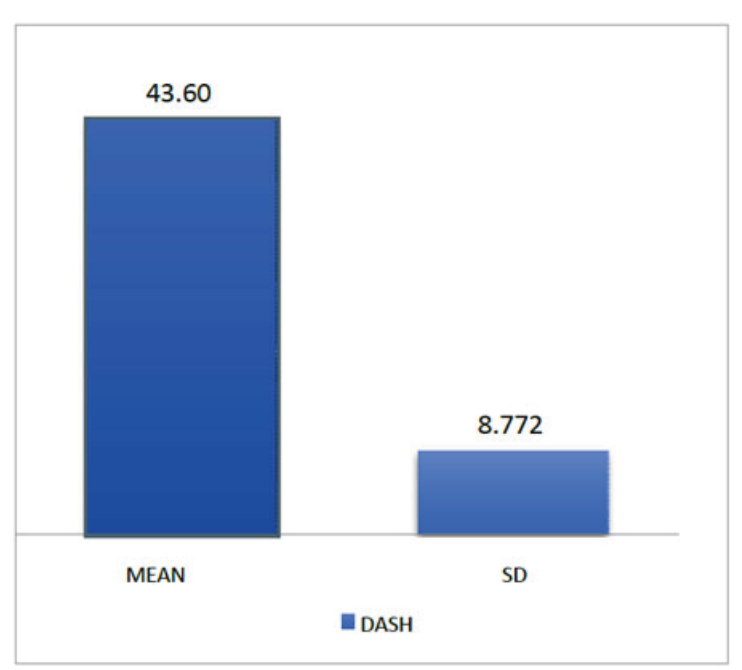

The bar diagram shows the mean and standard deviation of the Dash score

The graph shows the presence of a moderate amount of difficulty in the upper extremity of paramedical students at Parul University.

\section{DISCUSSION}

The present study was conducted to know the prevalence of musculoskeletal disorders among the paramedical students at Parul University due to the extensive usage of handheld devices. Within the study, the data was distributed and collected in the form of a questionnaire from the campus of Parul University in Vadodara. Subjects responded to the questionnaire and data analysis was done. Based on the result that is obtained from the study, it can be stated that the students were having moderate difficulty in arm, shoulder 
and hand due to more usage of the hand-held device. It has been reported that University students use their average time texting, emailing, scheduling, and Internet browsing on their mobile phones. ${ }^{1}$

A study conducted by Barolo et al. states that there was 46$52 \%$ pain in the shoulder among the students and staff members who were using hand-held devices. ${ }^{15}$ According to a study conducted by Charu Eapen et al. (2010) it was found that $18.5 \%$ of respondents complained of symptoms sin the upper limb due to extensive usage of the cell phone and more than $50 \%$ complained that they were having thumb pain and it increased due to excessive texting on cell phones. More than $70 \%$ of the subjects complained that the symptoms they faced were due to excessive use of the mobile phone. ${ }^{16}$ The reasons for the musculoskeletal disorder also depends upon the nature of smartphone use, users use the smartphone with a single hand, which puts stress on the thumb as the thumb moves in $79 \%$ of its maximum range of motion in abduction within the abduction/adduction plane and $55 \%$ of its maximum range of motion flexion in the flexion/extension plane which results into thumb pain. ${ }^{17}$

Due to the overuse of the smartphone, there were continuous muscle contractions within the upper extremity and the neck which resulted in the microscopic damage of muscles, which lead to a collection of the fluid and an increase in pressure of the tissues within the intracellular and extracellular spaces which was the reason for increase within the pain. ${ }^{18}$

When there are continuous fast movements which are with more reputations and performed with more force it leads to fatigue of the muscle with ischemic and metabolic changes that damages the muscle enzyme function. The affected muscles and their tendons become more susceptible to microtears and inflammatory changes which is also responsible for the pain that persists while doing activities like texting as well as rest. ${ }^{16}$

The contributing factors are less spacing on the keyboard, size of the mobile, position of the thumb and the static load which is put on the thumb during text messaging on a handheld device. Static repeated motion done by the users leads to reduction within the blood circulation as a result of which the supply of nutrients reduces which causes pain and fatigue among the users. ${ }^{19}$

Sustained and prolong gripping, the repetitive movement of the thumb has led to musculoskeletal disorders in the thumb and the extrinsic musculature of the forearm. ${ }^{20}$

The wrist engages in repeated flexion-extension which puts stress on the carpal tunnel and it results in narrowing of the carpal tunnel as well there is an increase within the pressure of the carpel tunnel, also there is a decrease within the space for the median nerve. ${ }^{21}$ Due to the posture of the wrist it has been stated that the extensive usage of the smartphone may affect the flexor pollicis tendon, thumb joint and median nerve $^{22}$

\section{CONCLUSION}

This study aimed to determine the prevalence's of musculoskeletal disorders among the paramedical student of Parul University. Usage of cell phones is crucial; however, more use of cell phones may lead to serious musculoskeletal disorders. Even though the musculoskeletal disorders within the upper extremity due to handheld devices can be treated with proper rehabilitation, users need to understand the risk factors and prevention of the disorders and the users are advised to decrease the total amount of time on the usage of the device. The study concluded that there was the presence of moderate musculoskeletal disorders in the upper extremities among the students due to extensive usage of Hand-held devices. Further studies involving the identification of risk factors in a larger population are recommended to prevent the disorders.

\section{SUMMARY}

This study was conducted to know the presence of musculoskeletal disorders in the upper extremity among paramedical students of the Parul University at Vadodara, due to extensive usage of Hand-held devices. This study included 209 subjects age between 18-25 years. The purpose for conducting the study was explained to students and the subjects were given a brief introduction regarding the study and the questionnaire. Data was collected in the form of Google Forms. The subjects were selected based on the inclusion and exclusion criteria and data analysis was done through the SPSS software version 20 .

Thus, the study concluded that there was the presence of a moderate amount of musculoskeletal disorders within the upper extremity among paramedical students of the Parul University due to extensive usage of hand-held devices

\section{FURTHER RECOMMENDATION}

o The duration and the time interval of the study should be increased along with the increase in sample size.

o The study should also be conducted in different locations and the professions which have high usage of hand-held devices should be included within the study.

\section{ACKNOWLEDGEMENT}

We acknowledge Parul University, Vadodara, Gujarat for their help in doing this work. 


\section{Conflict of interest: None}

\section{Funding: None}

Name of the authors and their contribution

1. Dr. Didhiti Desai - Concepts, design, the definition of intellectual content, literature search, data acquisition, manuscript preparation, manuscript editing, and manuscript review

2. Ishita Goswami - Literature search, manuscript preparation, manuscript editing

3. Umang Vaghela - Literature search, manuscript preparation, manuscript editing.

4. Darshana Chauhan - Literature search, manuscript preparation, manuscript editing.

\section{REFERENCES}

1. Balakrishnan R, Chinnavan E, Feii T. An extensive usage of hand-held devices will lead to musculoskeletal disorder of upper extremity among students in AMU: Int. j. Phys. educ. sports health .2016;3(2):368-72.

2. Hogg NA. Design of thumb keyboards: Performance, effort and kinematics (Master's thesis, University of Waterloo).

3. Sharan D, Mohandoss M, Ranganathan R, Jose JA, Rajkumar JS. Distal upper extremity disorders due to extensive usage of hand-held mobile devices. Human Factors in Organisational Des Manag. 2012; 51:1041-5.

4. Zhang Y, Lv S, Li C, Xiong Y, Zhou C, Li X, Ye M. Smartphone use disorder and future time perspective of college students: the mediating role of depression and moderating role of mindfulness. Child and Adol Psych Mental Health. 2020Dec;14(1):1-1.

5. Alruzayhi MK, Almuhaini MS, Alwassel AI, Alateeq OM. The effect of smartphone usage on the upper extremity performance among Saudi Youth, KSA. Rom J Rhinol. . 2018 Mar1;8(29):4753.

6. Alruzayhi MK, Almuhaini MS, Alwassel AI, Alateeq OM. The effect of smartphone usage on the upper extremity performance among Saudi Youth, KSA. Rom J Rhinol. 2018 Mar1;8(29):4753.

7. Alosaimi FD, Alyahya H, Alshahwan H, Al Mahyijari N, Shaik SA. Smartphone addiction among university students in Riyadh, Saudi Arabia.Saudi Med J.2016Jun;37(6):675.

8. Barkley JE, Lepp A. Cellular telephone use during free-living walking significantly reduces average walking speed. BMC Rese Notes. 2016 Dec1;9(1):195.
9. Barkley JE,Lepp A, Salehi-EsfahaniS .Collegestudents'mobilet elephone use is positively associated with sedentary behaviour. Ash J Med. 2016 Nov;10(6):437-41.

10. Gold JE, Driban JB, Thomas N, Chakravarty T, Channell V, Komaroff EG. Postures, typing strategies, and gender differences in mobile device usage: An observational study. Appl Ergon. 2012 Mar1;43(2):408-12.

11. Kwon M, Lee JY, Won WY, Park JW, Min JA, Hahn C, Gu X, Choi JH, Kim DJ. Development and validation of a smartphone addiction scale (SAS). PloS one. 2013 Feb 27;8(2):e56936.

12. Trudeau MB, Young JG, Jindrich DL, Dennerlein JT. Thumb motor performance varies with thumb and wrist posture during single-hand held mobile phone use.J. Biomech.. 2012 Sep21;45(14):2349-54.

13. 13. Xie Y, Szeto G, Dai J. Prevalence and risk factors associated with musculoskeletal complaints among users of mobile handheld devices: A systematic review. Applied ergonomics. 2017 Mar 1; 59:132-42.

14. Beaton DE, Katz JN, Fossel AH, Wright JG, Tarasuk V, Bombardier C. Measuring the whole or the parts? validity, reliability, and responsiveness of the Disabilities of the Arm, Shoulder and Hand outcome measure in different regions of the upper extremity. $J$ Hand Ther. 2001 Apr1;14(2):128-42.

15. Can S, Karaca A. Determination of musculoskeletal system pain, physical activity intensity, and prolonged sitting of university students using a smart phone.

16. Eapen C, Kumar B, Bhat AK. Prevalence of cumulative trauma disorders in cell phone users. J. Musculoskelet. Res.. 2010Sep;13(03):137-45.

17. Berolo S, Wells RP, Amick III BC. Musculoskeletal symptoms among mobile handheld device users and their relationship to device use: a preliminary study in a Canadian university population. Applied ergonomics. 2011 Jan1;42(2):371-8.

18. Kim GY, Ahn CS, Jeon HW, Lee CR. Effects of the use of smartphones on pain and muscle fatigue within the upper extremity. $\mathrm{J}$. Phys. Ther. and variant.2012;24(12):1255-

19. Kim HJ, KimJS. There relationship between smartphone use and subjective musculoskeletal symptoms and university students. J. Phys. Ther. and variant.2015;27(3):575-9.

20. Gustafsson E, Johnson PW, Hagberg M. Thumb postures and physical loads during mobile phone use A comparison of young adults with and without musculoskeletal symptoms. J Electromyogr Kinesiol J Electromyogr Kines. 2010 Feb1;20(1):127-35.

21. Bower JA, Stanisz GJ, Keir PJ. An MRI evaluation of carpal tunnel dimensions in healthy wrists: implications for carpal tunnel syndrome.Clinical Biomech.2006Oct1;21(8):816- 25

22. İNal EE, Demirci K, ÇetİntürkA, Akgönül M, Savaş S. Effects of smartphone overuse on hand function, pinch strength, and the median nerve. Muscle \& nerve. 2015Aug;52(2):183-8. 